\section{Review Article}

Check for updates

\title{
Contemporary Imaging Diagnosis of Cardiac Amyloidosis
}

\author{
Seung-Pyo Lee $\mathbb{D}, \mathrm{MD}, \mathrm{PhD}$ ', Jun-Bean Park $(\mathbb{D}, \mathrm{MD}, \mathrm{PhD}$ ',

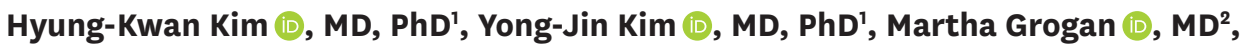 \\ and Dae-Won Sohn $\mathbb{D}^{\mathrm{D}}, \mathrm{MD}, \mathrm{PhD}{ }^{1}$
}

'Department of Internal Medicine, Seoul National University Hospital, Seoul, Korea

${ }^{2}$ Department of Cardiovascular Diseases, Mayo Clinic, Rochester, MN, USA

Received: Nov 26, 2018

Accepted: Dec 26, 2018

Address for Correspondence:

Seung-Pyo Lee, MD, PhD

Cardiovascular Center and Department of Internal Medicine, Seoul National University Hospital, 101 Daehak-ro, Jongno-gu, Seoul 03080, Korea.

E-mail: sproll1@snu.ac.kr

Copyright (c) 2019 Korean Society of Echocardiography

This is an Open Access article distributed under the terms of the Creative Commons Attribution Non-Commercial License (https:// creativecommons.org/licenses/by-nc/4.0/) which permits unrestricted non-commercial use, distribution, and reproduction in any medium, provided the original work is properly cited.

ORCID iDs

Seung-Pyo Lee (D)

https://orcid.org/0000-0002-5502-3977

Jun-Bean Park (D)

https://orcid.org/0000-0003-4053-8713

Hyung-Kwan Kim (D)

https://orcid.org/0000-0001-7950-2131

Yong-Jin Kim (iD)

https://orcid.org/0000-0002-1366-432X

Martha Grogan (D)

https://orcid.org/0000-0002-2541-4440

Dae-Won Sohn (iD)

https://orcid.org/0000-0002-1092-3285

Conflict of Interest

The authors have no financial conflicts of interest.

\section{INTRODUCTION}

Cardiac amyloidosis is defined as an abnormal cardiac deposit of proteins that are not native to the heart, generally insoluble, and resistant to proteolysis. ${ }^{1)}$ These proteins accumulate in the extracellular space of the myocardium, more accurately in the subsarcolemma, and lead to direct cell toxicity, cell death, and expansion of the extracellular space. Clinically, deposition of amyloid proteins in the heart causes thickening of the ventricular wall, diastolic dysfunction, and eventually, heart failure and sudden cardiac death. Over 10 proteins have been identified to cause cardiac amyloidosis to date; however, the majority of abnormal proteins frequently encountered are light chain immunoglobulin (AL), wild type transthyretin (wtTTR), and mutant transthyretin (mtTTR). An amyloid protein is noted with a letter ' $\mathrm{A}$ ' in front of the name. For example, the amyloid form of transthyretin (TTR) is noted as ATTR and the amyloid light chain as AL.

Cardiac amyloidosis is a rare disease. In the US, the prevalence of AL type is estimated to be approximately 1 in 10 million $^{233}$ and is almost always associated with plasma cell dyscrasia. Although the prevalence of ATTR cardiac amyloidosis has never been investigated systematically, there have been reports demonstrating that wtTTR cardiac amyloidosis might be underestimated in the elderly population ${ }^{4}$; its prevalence has been reported to be up to $25 \%$ in those 80 years or older. ${ }^{5)}$ In line with others, ${ }^{677}$ we also found that there is a group of patients with incidental 
cardiac amyloidosis and severe aortic stenosis, and that this is linked to ventricular dysfunction, suggesting possible clinical relevance of 'incidental' cardiac amyloidosis.

\section{DIAGNOSIS OF CARDIAC AMYLOIDOSIS}

The gold standard diagnostic method of cardiac amyloidosis is identification of abnormal proteins deposited abundantly in the heart to cause organ dysfunction. Before invasive tools are employed for definite diagnosis, there are certain clues that indicate clinical suspicion of cardiac amyloidosis. Cardiac amyloidosis is often diagnosed late, with an average time from initial symptoms to definite diagnosis of at least 6 months. ${ }^{8}$ This results in significant delays in appropriate treatment, which highlights the importance of clinical suspicion. We will list some typical findings in noninvasive tests with relevant references. The clinical presentation of cardiac amyloidosis may be very diverse; therefore, absence of the listed findings does not preclude disease absence.

\section{2-LEAD ELECTROCARDIOGRAM}

An abnormal finding occurs in up to $90 \%$ of patients with cardiac amyloidosis. ${ }^{9} \mathrm{~A}$ typical 12-lead electrocardiogram finding in patients with cardiac amyloidosis is a low QRS voltage in the limb leads, especially in spite of increased left ventricular (LV) wall thickness (Figure 1A) ${ }^{10)}$ Low voltage QRS is extremely rare in other diseases that frequently present with a thickened LV wall such as hypertrophic cardiomyopathy, aortic stenosis, or hypertension (Figure 1B). The presence of low QRS voltage portends a worse outcome in cardiac amyloidosis patients. ${ }^{11)} \mathrm{A}$ pseudoinfarction pattern, defined as QS waves in any two consecutive leads, is also a common finding (Figure 1C). Interestingly, these findings may be present irrespective of increased ventricular wall thickness. These findings may be even more prevalent in patients without increased ventricular wall thickness. ${ }^{10)}$

The above listed electrocardiographic findings are found more commonly in those with the AL type than the ATTR type. Despite these findings, the prevalence of typical electrocardiographic findings does not exceed $50 \%$; thus, absence of low QRS voltage or the pseudoinfarction pattern does not exclude the possibility of cardiac amyloidosis.

\section{ECHOCARDIOGRAPHY}

Cardiac amyloidosis should be suspected in any patient with symptoms or signs of unexplained heart failure, especially when LV wall thickness is increased and when there is prominent diastolic dysfunction (Figures $\mathbf{2 A}$ and B). Typically, cardiac amyloidosis may present as concentric thickening of the ventricular wall as opposed to hypertrophic cardiomyopathy, in which localized ventricular thickening is more common. Before harmonic imaging was commonly used, the ventricular wall of cardiac amyloidosis patients was described as having a 'sparkling or speckled appearance,' but this finding is now considered obsolete. ${ }^{12}$ Also, cardiac amyloidosis may be present without thickening of the LV wall. ${ }^{13)}$ Additionally, valvular thickening or pericardial effusion may also be evident with biatrial enlargement that reflects chronic diastolic dysfunction (Figure 2C). Diastolic dysfunction, increased wall thickness, atrial enlargement, and pericardial effusion are all independent 

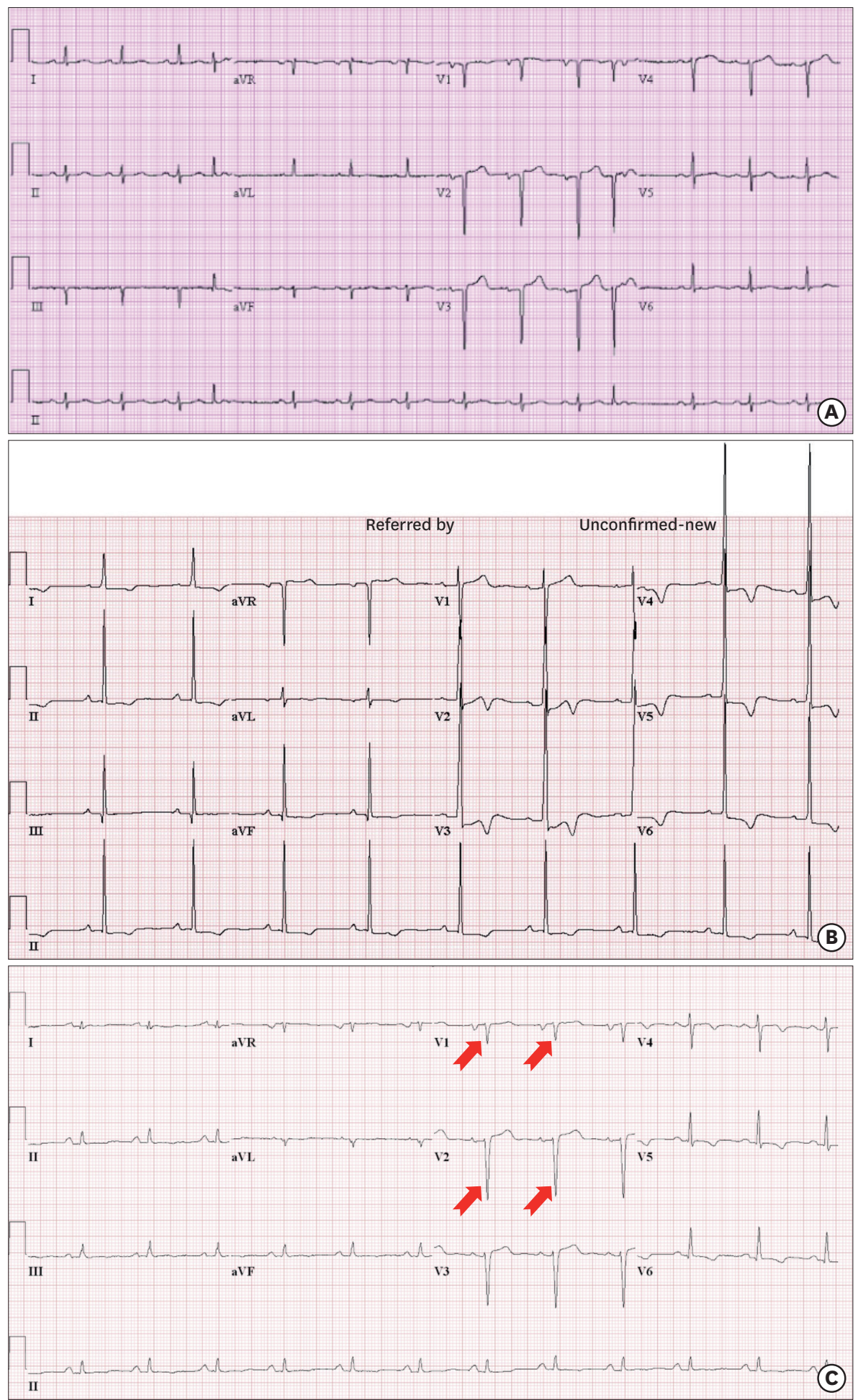

Figure 1. Examples of 12-lead electrocardiograms of cardiac amyloidosis patients. (A, B) Two patients with a similar degree of LV wall thickness, $15 \mathrm{~mm}$. A is a case of cardiac amyloidosis, and B is a case of the concentric form of hypertrophic cardiomyopathy. (A) Despite increased ventricular wall thickness, there is no evidence of ventricular hypertrophy on electrocardiograms. The QRS voltage, especially in the limb leads and the lateral precordial leads, is rather low considering the presence of thickened left ventricular wall. (B) This is in contrast to a significant increase of QRS voltage in patients with hypertrophic cardiomyopathy. (C) A pseudoinfarction pattern in a patient with cardiac amyloidosis. A typical QS wave (red arrows) can be seen in the septal precordial leads and can be misdiagnosed as myocardial infarction. 

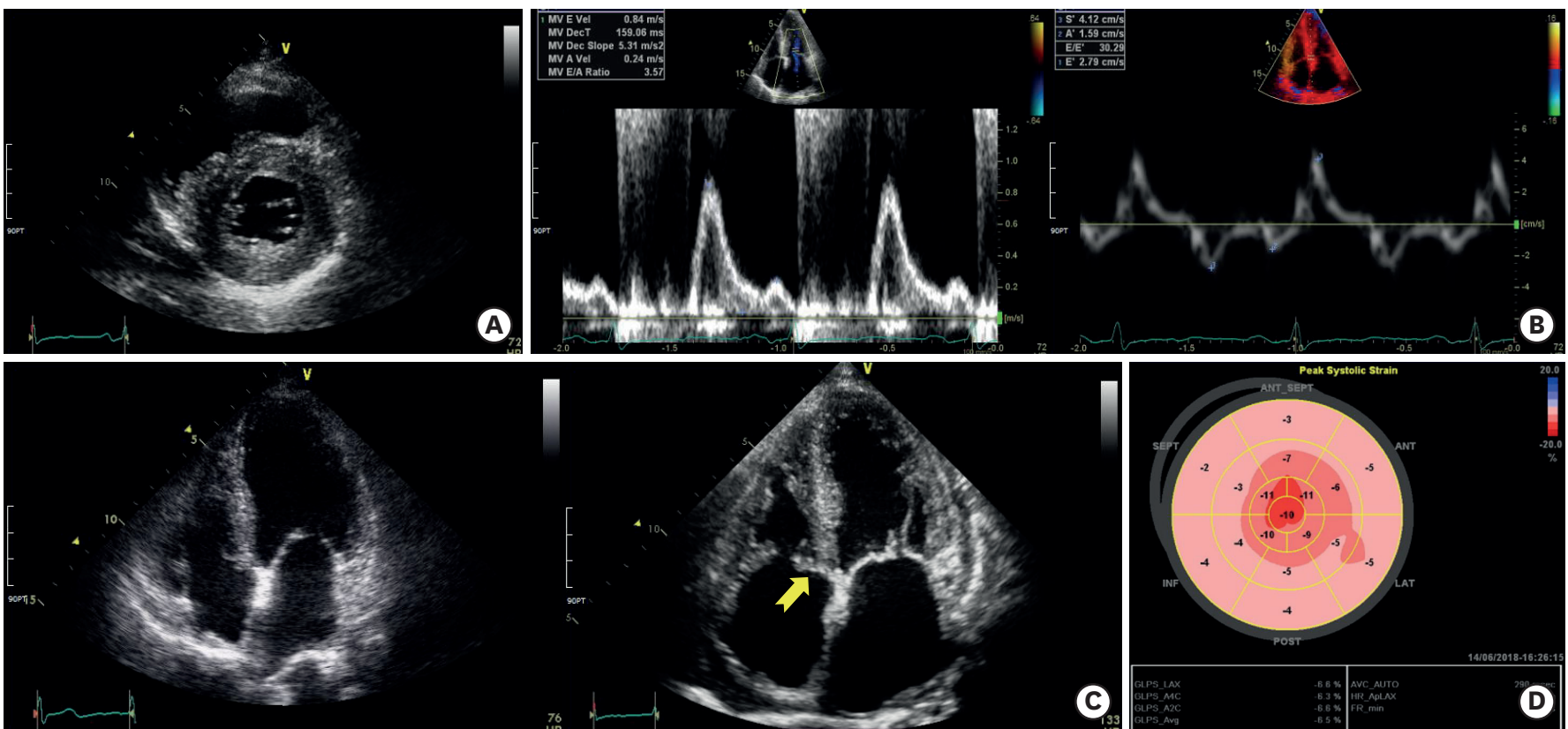

Figure 2. Typical echocardiography features in cardiac amyloidosis patients. (A) Thickened LV wall that measures up to $14 \mathrm{~mm}$ on parasternal view. (B) Doppler interrogation demonstrates a restrictive filling pattern in the mitral inflow study and very low $\mathrm{e}^{\prime}$ velocity at the mitral septal annulus. Calculation of $\mathrm{E} / \mathrm{e}^{\prime}$ is estimated to be 30, which indicates high LV filling pressure. (C) An angina patient who developed cardiac amyloidosis after 5 years of percutaneous coronary intervention. The LV wall thickness at the time of coronary intervention was normal, as were the sizes of both atria (left panel). The patient visited the hospital for progressive dyspnea and significant thickening of the ventricular wall, and biatrial enlargement was noted (right panel). Note thickening of the tricuspid valve at the time of diagnosis of cardiac amyloidosis (yellow arrows) that was not evident on initial echocardiography. (D) A representative bull's eye plot of longitudinal strain. Note that the longitudinal strain of the apex is preserved in contrast to those of the other midventricular or basal segments.

prognosticators in patients with cardiac amyloidosis. ${ }^{91416)}$ Although the degree of ventricular wall thickening may be more severe in those with ATTR than in those with AL cardiac amyloidosis ${ }^{17)}$ direct comparison of ventricular structure and function between ATTR and AL cardiac amyloidosis remains to be confirmed in a larger cohort.

Perhaps the most up-to-date echocardiographic modality used for diagnosis and risk stratification of cardiac amyloidosis is strain imaging, generally using speckle tracking echocardiography. A typical strain image of a patient with cardiac amyloidosis is an 'apical sparing' or a 'cherry-on-top' pattern on the bull's eye plot of global longitudinal strain (Figure 2D). ${ }^{18)}$ Although not validated in other studies, this apical sparing pattern was shown to have $93 \%$ sensitivity and $82 \%$ specificity for diagnosing cardiac amyloidosis, and its visual assessment is useful for diagnosing less advanced stages of cardiac amyloidosis. ${ }^{19)}$ Longitudinal ventricular dysfunction by strain imaging, whether at the basal level or globally, signals poor prognosis in those with AL cardiac amyloidosis. ${ }^{16202021)}$ The prognostic value of strain imaging in ATTR cardiac amyloidosis remains to be investigated in further studies. ${ }^{22)}$

\section{CARDIOVASCULAR MAGNETIC RESONANCE}

Cardiovascular magnetic resonance (CMR) is a versatile imaging method for analyzing myocardial texture and has been rapidly adopted for clinical use in patients with suspected cardiac amyloidosis. This is based on the seminal discovery of the difference in gadolinium kinetics of the myocardium between normal and amyloidosis patients. ${ }^{23)}$ 

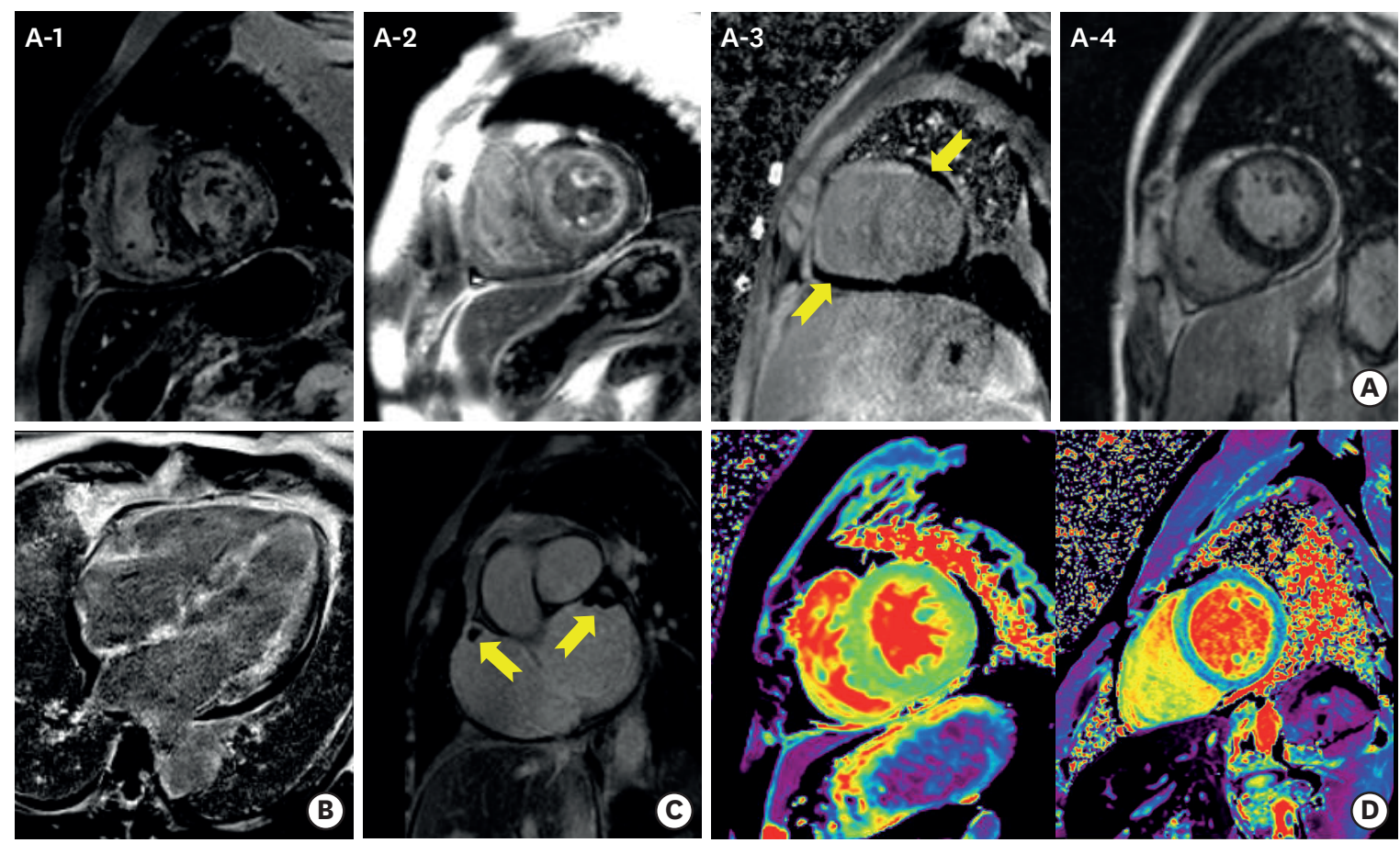

$2,000 \mathrm{~ms}$

Native $\mathrm{T} 1$ (ms)

Figure 3. Cardiovascular magnetic resonance (CMR) images of cardiac amyloidosis patients. (A) The pattern of late gadolinium enhancement (LGE) can be diverse in cardiac amyloidosis patients. Although multifocal patchy LGE (A-1) and global subendocardial ring enhancement patterns (A-2) are most common, suboptimal nulling is not unusual (A-3) and even no LGE (A-4) in spite of cardiac amyloidosis on myocardial biopsy. Pericardial effusion is also noted (A-3, yellow arrows). (B) Along with subendocardial LGE in the ventricle, LGE may also be seen in the interatrial septum. (C) Analysis for the presence of intracardiac thrombi in patients with cardiac amyloidosis is important, as in this case in which thrombi were noted at both atria (yellow arrows). (D) Parametric CMR is easy to quantify and gives information on diffuse myocardial change. A typical case of cardiac amyloidosis with an elevated septal native T1 up to 1,550 msec (left panel). A CMR scan of a normal volunteer with a native $\mathrm{T} 1 \mathrm{of} 1,150 \mathrm{msec}$ (right panel).

The pattern of late gadolinium enhancement (LGE) in the myocardium is heterogeneous, ranging from the global transmural or subendocardial LGE pattern to patchy focal LGE to suboptimal myocardial nulling (Figure 3A), which may match the deposition pattern of interstitial amyloid. ${ }^{24}$ Incidental findings such as atrial enhancement (Figure 3B) or thrombus (Figure 3C) may also be detected on CMR, given its superiority in signal-to-noise ratio to echocardiography.

Based on the histologic background that amyloid is deposited in the interstitium, several investigators have looked into the possibility of using parametric CMR for assessment of cardiac amyloidosis, the utility of which has been demonstrated elsewhere. ${ }^{2526)}$ Either by measurement of native $\mathrm{T} 1$ or by calculation of extracellular volume (ECV) fraction (Figure 3D), the myocardium of cardiac amyloidosis patients has been shown to have higher native T1 or ECV. ${ }^{27228)}$ Although the majority of these studies have used specialized sequences for T1 mapping, such as modified look-locker inversion recovery (MOLLI) sequence or shortened MOLLI (shMOLLI) sequence, this strategy can also be adopted with the post-contrast conventional SSFP sequence that is used for cine imaging. ${ }^{29}$ Recent investigations have shown that the presence of LGE on CMR is a robust predictor of outcome, ${ }^{30}$ independent of other known cardiac biomarkers. ${ }^{31}$ The degree of myocardial edema, measured with the use of $\mathrm{T} 2$ imaging, has also been shown to be an independent prognosticator. ${ }^{32}$

The validity of CMR in ATTR cardiac amyloidosis is not as well established as in AL cardiac amyloidosis, but there is no evident reason that the clinical validity of CMR in the ATTR type 
would be different from that in the AL type. However, the number of patients studied is much smaller, and most of the investigations are single-center studies. Nonetheless, the pattern of ventricular hypertrophy that can be precisely evaluated using cine CMR and the degree of ECV may be useful for evaluation of ATTR cardiac amyloidosis. ${ }^{33)}$ Although unvalidated in larger populations, the pattern of LGE also may be used for differentiation between $\mathrm{AL}$ and ATTR $^{3435)}$ amyloidosis.

In spite of the accumulating evidence of the value of CMR in diagnosis, differentiation, and prognostication of cardiac amyloidosis, there are some limitations. Renal dysfunction, which is commonly seen in systemic amyloidosis patients, is a contraindication for gadolinium use. Furthermore, diagnosis of cardiac amyloidosis with CMR relies on the pattern of LGE and, as such, the false-positive rate of up to $5 \%$ cannot be overlooked. ${ }^{34)}$

\section{NUCLEAR SCINTIGRAPHY}

Since the initial finding that ${ }^{99 \mathrm{~m}} \mathrm{Tc}$-diphosphonates can image amyloid deposits in the soft tissue, ${ }^{36)}$ bone imaging tracers that are based on diphosphonates tagged with ${ }^{99 \mathrm{~m}} \mathrm{Tc}$, such as ${ }^{99 \mathrm{~m}} \mathrm{Tc}$-pyrophosphate ( $\left.{ }^{99 \mathrm{~m}} \mathrm{Tc}-\mathrm{PYP}\right),{ }^{99 \mathrm{~m}} \mathrm{Tc}-$ methylene diphosphonate $\left({ }^{99 \mathrm{~m}} \mathrm{Tc}-\mathrm{MDP}\right)$, ${ }^{99 \mathrm{~m}} \mathrm{Tc}$-hydroxymethylene diphosphonate $\left.{ }^{99 \mathrm{~m}} \mathrm{Tc}-\mathrm{HPD}\right)$, and ${ }^{99 \mathrm{~m}} \mathrm{Tc}-3,3-$ diphosphono-1,2propanodicarboxylic acid ( $\left.{ }^{99 \mathrm{~m}} \mathrm{Tc}-\mathrm{DPD}\right)$, have long been used for visualization of amyloid deposits in the heart (Figure 4A). However, the theoretical basis of why these single-photon emission computed tomography (SPECT) agents bind to TTR is still not well understood. Of these agents, ${ }^{99 \mathrm{~m}} \mathrm{Tc}$-DPD has been the most extensively studied. The binding of ${ }^{99 \mathrm{~m}} \mathrm{Tc}-\mathrm{DPD}$ to amyloid deposits in the heart seems to be more specific to the ATTR type than the AL type. ${ }^{3738)}$ The binding of ${ }^{99 \mathrm{~m}} \mathrm{Tc}-\mathrm{DPD}$ does not seem to differentiate between wtTTR and mtTTR, as shown in a report of a series of mtTTR-related cardiac amyloidoses. ${ }^{39}$ Moreover, quantification of tracer retention in the myocardium reflects the severity of myocardial involvement. ${ }^{40)}$

Contrary to ${ }^{99 \mathrm{~m}} \mathrm{Tc}$-diphosphonate SPECT tracers, recently developed positron emission tomography (PET) tracers are made to directly target the amyloid protein itself and stem from the findings in patients with Alzheimer's disease, a disease of amyloid accumulation in the brain parenchyme. ${ }^{4142)} \mathrm{We}$ and others were among the first to report the clinical utility of ${ }^{11} \mathrm{C}$-Pittsburgh $\mathrm{B}(\mathrm{PiB})$ compound in imaging cardiac amyloidosis, albeit with some differences in acquisition protocol (Figure 4B). ${ }^{1943)}$ The ${ }^{11} \mathrm{C}-\mathrm{PiB}$ compound also has the potential to monitor the degree of amyloid deposition during or after appropriate chemotherapy (Figure 4C), but evidence supporting this is largely lacking. Although the experience in our center is limited, a few investigators have also reported use of ${ }^{11} \mathrm{C}-\mathrm{PiB}$ in ATTR cardiac amyloidosis. ${ }^{44}$

However, because of the short half-life of ${ }^{11} \mathrm{C}\left(\mathrm{t}_{1 / 2} \approx 20\right.$ minutes) and the need for an on-site cyclotron, the majority of amyloid PET tracers is now labeled with ${ }^{18} \mathrm{~F}$-tagged radiotracers such as ${ }^{18} \mathrm{~F}\left(\mathrm{t}_{1 / 2} \approx 110\right.$ minutes), ${ }^{18} \mathrm{~F}$-florbetapir, or ${ }^{18} \mathrm{~F}$-florbetaben. Following initial successful pilot studies using these ${ }^{18} \mathrm{~F}$ PET tracers, ${ }^{45}{ }^{46)}$ these ${ }^{18} \mathrm{~F}$-tagged radiotracers have been shown to accumulate specifically at sites of amyloid deposit. ${ }^{47)}$ Although not specific for amyloid, recent reports have shown that ${ }^{18} \mathrm{~F}-\mathrm{NaF}$ also may be used for imaging cardiac amyloidosis. ${ }^{48}$ ) 

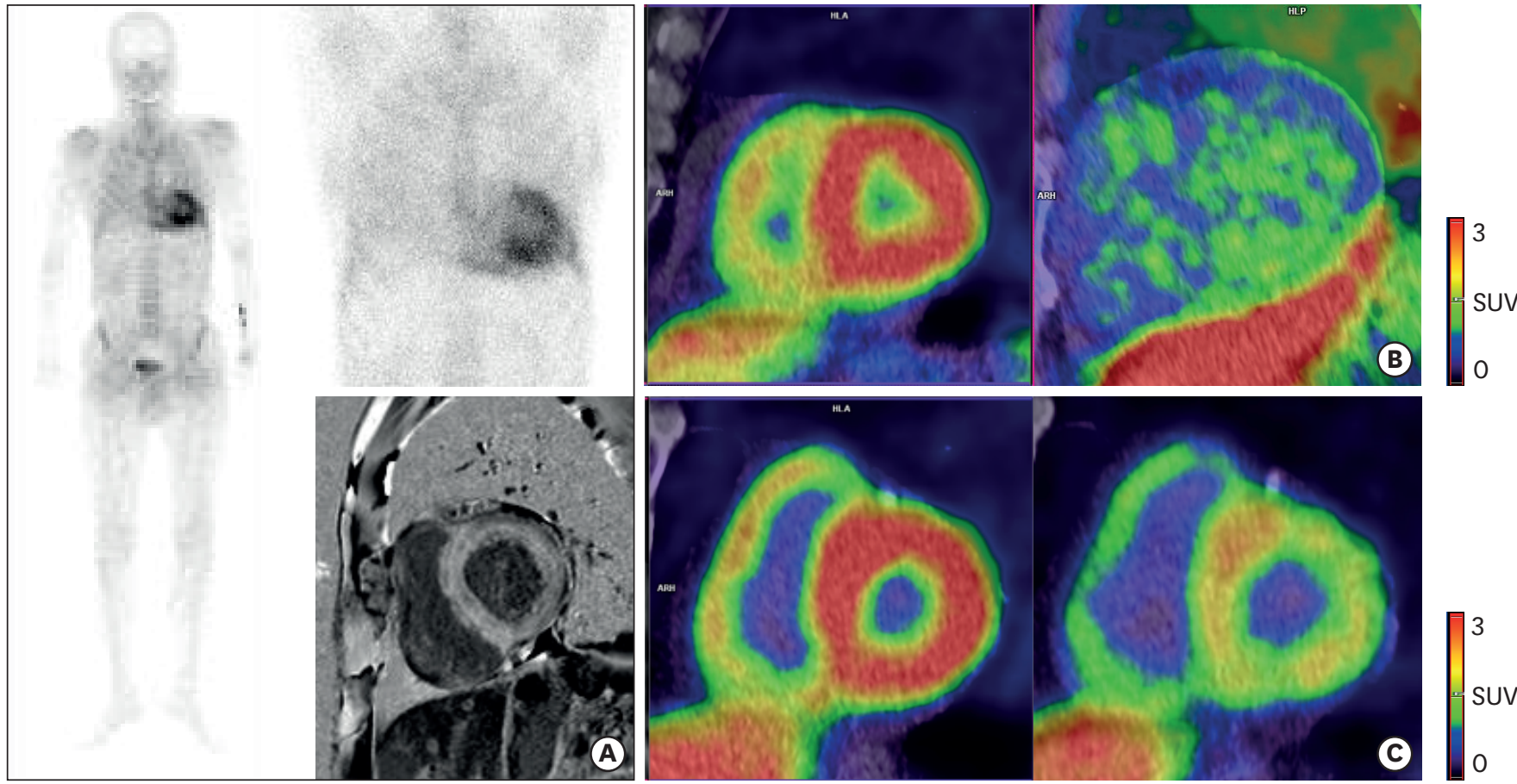

Figure 4. Nuclear imaging in diagnosis of cardiac amyloidosis and follow-up. (A) A representative image of 99mTC-DPD SPECT in an ATTR cardiac amyloidosis patient. Evident uptake of ${ }^{99 \mathrm{~m} T C-D P D}$ in the myocardium is noted and is supported by suboptimal nulling on CMR. (B) Uptake of ${ }^{11} \mathrm{C}$-Pittsburgh B (PiB) compound in a patient with biopsy-proven cardiac amyloidosis (left panel). This compound is specific for amyloid deposits as no "C-PiB is noted in healthy volunteers (right panel). (C) A significant decrease of "C-PiB uptake in a patient with cardiac amyloidosis 12 months after chemotherapy and autologous stem cell transplantation (left panel; before chemotherapy, right panel).

\section{CONCLUSION}

Although cardiac amyloidosis is not a common disease, the diverse presentation often leads to misdiagnosis and inappropriate delays in adequate treatment. Therefore, clues that point toward diagnosis of this disease are important. Various imaging studies are utilized to clarify suspicion, to diagnose the disease noninvasively, and possibly for follow-up of the disease course.

Not all of the aforementioned studies may be needed in every patient. There are some pitfalls to consider in each test, some of which have been covered in this review. However, we believe that careful consideration of these tests is needed in patients with suspected or diagnosed cardiac amyloidosis, so that each patient will receive the optimal, tailored care needed.

\section{REFERENCES}

1. Merlini G, Bellotti V. Molecular mechanisms of amyloidosis. N Engl J Med 2003;349:583-96. PUBMED | CROSSREF

2. Kyle RA, Linos A, Beard CM, et al. Incidence and natural history of primary systemic amyloidosis in Olmsted County, Minnesota, 1950 through 1989. Blood 1992;79:1817-22. PUBMED

3. Pinney JH, Smith CJ, Taube JB, et al. Systemic amyloidosis in England: an epidemiological study. $\mathrm{Br} J$ Haematol 2013;161:525-32. PUBMED | CROSSREF 
4. Mohammed SF, Mirzoyev SA, Edwards WD, et al. Left ventricular amyloid deposition in patients with heart failure and preserved ejection fraction. JACC Heart Fail 2014;2:113-22. PUBMED | CROSSREF

5. Cornwell GG 3rd, Murdoch WL, Kyle RA, Westermark P, Pitkänen P. Frequency and distribution of senile cardiovascular amyloid. A clinicopathologic correlation. Am J Med 1983;75:618-23. PUBMED | CROSSREF

6. Treibel TA, Fontana M, Gilbertson JA, et al. Occult transthyretin cardiac amyloid in severe calcific aortic stenosis: prevalence and prognosis in patients undergoing surgical aortic valve replacement. Circ Cardiovasc Imaging 2016;9:e005066. PUBMED | CROSSREF

7. Castaño A, Narotsky DL, Hamid N, et al. Unveiling transthyretin cardiac amyloidosis and its predictors among elderly patients with severe aortic stenosis undergoing transcatheter aortic valve replacement. Eur Heart J 2017;38:2879-87. PUBMED | CROSSREF

8. Lousada I, Comenzo RL, Landau H, Guthrie S, Merlini G. Light chain amyloidosis: patient experience survey from the Amyloidosis Research Consortium. Adv Ther 2015;32:920-8. PUBMED | CROSSREF

9. Mohty D, Damy T, Cosnay P, et al. Cardiac amyloidosis: updates in diagnosis and management. Arch Cardiovasc Dis 2013;106:528-40. PUBMED | CROSSREF

10. Murtagh B, Hammill SC, Gertz MA, Kyle RA, Tajik AJ, Grogan M. Electrocardiographic findings in primary systemic amyloidosis and biopsy-proven cardiac involvement. Am J Cardiol 2005;95:535-7. PUBMED | CROSSREF

11. Mussinelli R, Salinaro F, Alogna A, et al. Diagnostic and prognostic value of low QRS voltages in cardiac AL amyloidosis. Ann Noninvasive Electrocardiol 2013;18:271-80. PUBMED | CROSSREF

12. Aljaroudi WA, Desai MY, Tang WH, Phelan D, Cerqueira MD, Jaber WA. Role of imaging in the diagnosis and management of patients with cardiac amyloidosis: state of the art review and focus on emerging nuclear techniques. J Nucl Cardiol 2014;21:271-83. PUBMED | CROSSREF

13. Lee GY, Kim K, Choi JO, et al. Cardiac amyloidosis without increased left ventricular wall thickness. Mayo Clin Proc 2014;89:781-9. PUBMED | CROSSREF

14. Klein AL, Hatle LK, Taliercio CP, et al. Prognostic significance of Doppler measures of diastolic function in cardiac amyloidosis. A Doppler echocardiography study. Circulation 1991;83:808-16. PUBMED | CROSSREF

15. Cueto-Garcia L, Reeder GS, Kyle RA, et al. Echocardiographic findings in systemic amyloidosis: spectrum of cardiac involvement and relation to survival. J Am Coll Cardiol 1985;6:737-43. PUBMED | CROSSREF

16. Bellavia D, Pellikka PA, Al-Zahrani GB, et al. Independent predictors of survival in primary systemic (Al) amyloidosis, including cardiac biomarkers and left ventricular strain imaging: an observational cohort study. J Am Soc Echocardiogr 2010;23:643-52. PUBMED | CROSSREF

17. Quarta CC, Solomon SD, Uraizee I, et al. Left ventricular structure and function in transthyretin-related versus light-chain cardiac amyloidosis. Circulation 2014;129:1840-9. PUBMED | CROSSREF

18. Phelan D, Collier P, Thavendiranathan $\mathrm{P}$, et al. Relative apical sparing of longitudinal strain using twodimensional speckle-tracking echocardiography is both sensitive and specific for the diagnosis of cardiac amyloidosis. Heart 2012;98:1442-8. PUBMED | CROSSREF

19. Lee SP, Lee ES, Choi H, et al. 11C-Pittsburgh B PET imaging in cardiac amyloidosis. JACC Cardiovasc Imaging 2015;8:50-9. PUBMED | CROSSREF

20. Koyama J, Falk RH. Prognostic significance of strain Doppler imaging in light-chain amyloidosis. JACC Cardiovasc Imaging 2010;3:333-42. PUBMED | CROSSREF

21. Buss SJ, Emami M, Mereles D, et al. Longitudinal left ventricular function for prediction of survival in systemic light-chain amyloidosis: incremental value compared with clinical and biochemical markers. $J$ Am Coll Cardiol 2012;60:1067-76. PUBMED | CROSSREF 
22. Siepen FAD, Bauer R, Voss A, et al. Predictors of survival stratification in patients with wild-type cardiac amyloidosis. Clin Res Cardiol 2018;107:158-69.

PUBMED | CROSSREF

23. Maceira AM, Joshi J, Prasad SK, et al. Cardiovascular magnetic resonance in cardiac amyloidosis. Circulation 2005;111:186-93.

PUBMED | CROSSREF

24. Syed IS, Glockner JF, Feng D, et al. Role of cardiac magnetic resonance imaging in the detection of cardiac amyloidosis. JACC Cardiovasc Imaging 2010;3:155-64.

PUBMED | CROSSREF

25. Lee SP, Lee W, Lee JM, et al. Assessment of diffuse myocardial fibrosis by using MR imaging in asymptomatic patients with aortic stenosis. Radiology 2015;274:359-69. PUBMED | CROSSREF

26. Lee H, Park JB, Yoon YE, et al. Noncontrast myocardial T1 mapping by cardiac magnetic resonance predicts outcome in patients with aortic stenosis. JACC Cardiovasc Imaging 2018;11:974-83. PUBMED | CROSSREF

27. Banypersad SM, Sado DM, Flett AS, et al. Quantification of myocardial extracellular volume fraction in systemic AL amyloidosis: an equilibrium contrast cardiovascular magnetic resonance study. Circ Cardiovasc Imaging 2013;6:34-9. PUBMED | CROSSREF

28. Karamitsos TD, Piechnik SK, Banypersad SM, et al. Noncontrast T1 mapping for the diagnosis of cardiac amyloidosis. JACC Cardiovasc Imaging 2013;6:488-97. PUBMED | CROSSREF

29. White JA, Kim HW, Shah D, et al. CMR imaging with rapid visual T1 assessment predicts mortality in patients suspected of cardiac amyloidosis. JACC Cardiovasc Imaging 2014;7:143-56. PUBMED | CROSSREF

30. Raina S, Lensing SY, Nairooz RS, et al. Prognostic value of late gadolinium enhancement cmr in systemic amyloidosis. JACC Cardiovasc Imaging 2016;9:1267-77. PUBMED | CROSSREF

31. Boynton SJ, Geske JB, Dispenzieri A, et al. LGE provides incremental prognostic information over serum biomarkers in AL cardiac amyloidosis. JACC Cardiovasc Imaging 2016;9:680-6.

PUBMED | CROSSREF

32. Kotecha T, Martinez-Naharro A, Treibel TA, et al. Myocardial edema and prognosis in amyloidosis. JAm Coll Cardiol 2018;71:2919-31. PUBMED | CROSSREF

33. Martinez-Naharro A, Treibel TA, Abdel-Gadir A, et al. Magnetic resonance in transthyretin cardiac amyloidosis. J Am Coll Cardiol 2017;70:466-77. PUBMED | CROSSREF

34. Dungu JN, Valencia O, Pinney JH, et al. CMR-based differentiation of AL and ATTR cardiac amyloidosis. JACC Cardiovasc Imaging 2014;7:133-42. PUBMED | CROSSREF

35. Kristen AV, aus dem Siepen F, Scherer K, et al. Comparison of different types of cardiac amyloidosis by cardiac magnetic resonance imaging. Amyloid 2015;22:132-41. PUBMED | CROSSREF

36. VanAntwerp JD, O'Mara RE, Pitt MJ, Walsh S. Technetium-99m-diphosphonate accumulation in amyloid. J Nucl Med 1975;16:238-40. PUBMED

37. Perugini E, Guidalotti PL, Salvi F, et al. Noninvasive etiologic diagnosis of cardiac amyloidosis using 99mTc-3,3-diphosphono-1,2-propanodicarboxylic acid scintigraphy. J Am Coll Cardiol 2005;46:1076-84. PUBMED | CROSSREF

38. Bokhari S, Castaño A, Pozniakoff T, Deslisle S, Latif F, Maurer MS. (99m)Tc-pyrophosphate scintigraphy for differentiating light-chain cardiac amyloidosis from the transthyretin-related familial and senile cardiac amyloidoses. Circ Cardiovasc Imaging 2013;6:195-201. PUBMED | CROSSREF

39. Rapezzi C, Quarta CC, Guidalotti PL, et al. Role of $(99 \mathrm{~m}) \mathrm{Tc}-\mathrm{DPD}$ scintigraphy in diagnosis and prognosis of hereditary transthyretin-related cardiac amyloidosis. JACC Cardiovasc Imaging 2011;4:659-70. PUBMED | CROSSREF

40. Kristen AV, Scherer K, Buss S, et al. Noninvasive risk stratification of patients with transthyretin amyloidosis. JACC Cardiovasc Imaging 2014;7:502-10.

PUBMED | CROSSREF 
41. Klunk WE, Engler H, Nordberg A, et al. Imaging brain amyloid in Alzheimer's disease with Pittsburgh Compound-B. Ann Neurol 2004;55:306-19.

PUBMED | CROSSREF

42. Bateman RJ, Xiong C, Benzinger TL, et al.. Clinical and biomarker changes in dominantly inherited Alzheimer's disease. N Engl J Med 2012;367:795-804.

PUBMED | CROSSREF

43. Antoni G, Lubberink M, Estrada S, et al. In vivo visualization of amyloid deposits in the heart with 11C-PIB and PET. J Nucl Med 2013;54:213-20.

PUBMED | CROSSREF

44. Pilebro B, Arvidsson S, Lindqvist P, et al. Positron emission tomography (PET) utilizing Pittsburgh compound B (PIB) for detection of amyloid heart deposits in hereditary transthyretin amyloidosis (ATTR). J Nucl Cardiol 2018;25:240-8.

PUBMED | CROSSREF

45. Dorbala S, Vangala D, Semer J, et al. Imaging cardiac amyloidosis: a pilot study using ${ }^{18} \mathrm{~F}$-florbetapir positron emission tomography. Eur J Nucl Med Mol Imaging 2014;41:1652-62.

PUBMED | CROSSREF

46. Law WP, Wang WY, Moore PT, Mollee PN, Ng AC. Cardiac amyloid imaging with 18F-florbetaben PET: a pilot study. J Nucl Med 2016;57:1733-9.

PUBMED | CROSSREF

47. Park MA, Padera RF, Belanger A, et al. 18F-florbetapir binds specifically to myocardial light chain and transthyretin amyloid deposits: autoradiography study. Circ Cardiovasc Imaging 2015;8:e002954. PUBMED | CROSSREF

48. Morgenstern R, Yeh R, Castano A, Maurer MS, Bokhari S. ${ }^{18}$ Fluorine sodium fluoride positron emission tomography, a potential biomarker of transthyretin cardiac amyloidosis. J Nucl Cardiol 2018;25:1559-67. PUBMED | CROSSREF 